\title{
CONTROLE SOCIAL NA REDE MUNDIAL DE COMPUTADORES COMO TUTELA DO MEIO AMBIENTE CULTURAL: ALGUMAS CONSIDERAÇÕES
}

\section{SOCIAL CONTROL IN WORLD NETWORK AS COMPUTER PROTECTION OF THE ENVIRONMENT THROUGH CULTURAL: SOME CONSIDERATIONS}

\author{
Regina Célia Martinez ${ }^{1}$ \\ André Felipe Soares de Arruda ${ }^{2}$ \\ Carolina Ferreira Souza ${ }^{3}$
}

\begin{abstract}
Resumo
O presente trabalho tem como objetivo investigar se, a fim de se preservar os bens ambientais culturais, é possível estabelecer o controle social na rede mundial de computadores (internet). É preciso avaliar se a rede, como ambiente livre, deve ou não sofrer alguma restrição ou controle, mesmo que para proteger minorias políticas. O controle social está previsto para a tutela do meio ambiente cultural no artigo 216-A, $\S 1$ 으 X da Constituição Federal. A opção metodológica foi por estudos e análises de resenha de literatura específica, legislação pertinente e doutrina. As conclusões são que a regulação do conteúdo deve ser feita na rede para as páginas de conteúdo das grandes corporações da mídia que, além de atuarem no rádio e na televisão, também estão na rede e pode ser feito em forma de cotas (conteúdos mínimos) de programação.
\end{abstract}

Palavras-chave: Controle social; Meio ambiente cultural; Rede mundial de computadores; Internet; Regulação.

\section{Abstract}

This study aims to investigate whether, in order to preserve cultural environmental goods, it is possible to establish social control on the world wide web (internet). We need to assess whether the network as a free environment, should or should not suffer any restriction or control, even to protect political minorities. Social control is provided for the protection of the cultural environment in Article 216-A, $\S 1, X$ of the Constitution. The methodological option was for studies and analysis of review of the literature, relevant legislation and doctrine. The conclusions are that the regulation of content should be made on the network to the content pages of large corporations the media, and act on radio and television, are also on the network and can be done in the form of quotas (minimum content) programming.

Keywords: Social control; Cultural environment; World Wide Web; Internet; Regulation.

\footnotetext{
${ }^{1}$ Doutora em Direito pela PUC- SP. Professora dos Cursos de Graduação e Mestrado em Direito da Sociedade da Informação das Faculdades Metropolitanas Unidas. Vice-presidente da Associação Paulista de Conservadores e Restauradores de Bens Culturais - São Paulo. Consultora Especialista do Conselho Estadual de Educação - São Paulo. Assessora do Comitê de Análise da Sociedade Brasileira para o Progresso da Ciência. Diretora do IBDC. E-mail: reginamarar@uol.com.br

${ }^{2}$ Doutorando em Direito das Relações Sociais pela Pontifícia Universidade Católica de São Paulo. Professor da Universidade Federal de Goiás, Regional Jataí. E-mail: andrefsarruda@gmail.com

${ }^{3}$ Doutoranda em Direito das Relações Sociais pela Pontifícia Universidade Católica de São Paulo. Professora da Universidade Federal de Goiás, Regional Jataí. E-mail: carolinafsouza@hotmail.com
} 


\section{INTRODUÇÃO}

O meio ambiente digital é um dos aspectos do meio ambiente, que, juntamente com os demais (meio ambiente natural; meio ambiente artificial; meio ambiente do trabalho; meio ambiente cultural; e patrimônio genético) é essencial à sadia qualidade de vida, responsável pela manutenção de um meio ambiente equilibrado, atendendo ao comando constitucional do art. 225.

O presente trabalho tem como objetivo investigar se, a fim de se preservar os bens ambientais culturais, é possível estabelecer o controle social na rede mundial de computadores (internet). É preciso avaliar se a rede, como ambiente livre, deve ou não sofrer alguma restrição ou controle, mesmo que para proteger minorias políticas.

Considerando-se que não existe legislação que autorize explicitamente tal regulação, serão apresentados dispositivos e Projetos de Lei referentes à democratização da mídia tradicional (rádio e televisão) que possam ser aplicados à rede mundial de computadores. O controle social está previsto para a tutela do meio ambiente cultural no artigo 216-A, $\S 10$, X da Constituição Federal, mesmo artigo que criou o Sistema Nacional de Cultura.

A opção metodológica foi por estudos e análises de resenha de literatura específica, legislação pertinente (Leis e Projetos de Lei) e doutrina. As conclusões são que a regulação do conteúdo deve ser feita na rede mundial de computadores para as páginas de conteúdo das grandes corporações da mídia que, além de atuarem no rádio e na televisão, também estão na rede. Além disso, esse controle social do meio ambiente cultural pode ser em forma de cotas (conteúdos mínimos) de programação e informação especialmente dos povos indígena e negro.

\section{MEIO AMBIENTE CULTURAL E MEIO AMBIENTE CULTURAL DIGITAL: CONCEITOS INICIAIS}

Temas centrais do presente trabalho são o meio ambiente cultural e suas implicações no meio ambiente digital (meio ambiente cultural digital). Serão apresentados alguns conceitos de cultura em áreas do conhecimento distintas do Direito, traçando algumas relações entre eles.

As ciências sociais, em suas diversas áreas, estudam, entre outros fenômenos, aqueles que se referem à cultura. A antropologia do século XIX traz uma definição mais ampla do que se empregava até então, proporcionando um conceito mais moderno. Burnett Tylor, em sua obra Primitive Culture, de 1871, define cultura como: "O complexo de conhecimentos, crenças, artes, 
leis, moral, hábitos, costumes e capacidades adquiridas pelos homens como membros de uma sociedade" (apud CUNHA, 2003, p. 195).

Alguns dos sentidos antigos de cultura, entretanto, ainda permaneciam durante o século XIX, como, por exemplo, que algumas sociedades possuem cultura e outras não, ou mesmo que, dentro de uma sociedade, alguns indivíduos são aculturados e outros não. Tais sentidos foram se alterando até se chegar à ideia de universalidade do fenômeno cultural, considerando-se que todos os povos, indistintamente, criam padrões e valores sociais. Individualmente, o fenômeno cultural passa a ser entendido como uma segunda natureza, exclusiva do ser humano (CUNHA, 2003, p. 196).

A partir desses novos conceitos, a cultura começa, portanto, a ser interpretada como sendo inerente a todo ser humano e, além disso, povos que eram considerados não civilizados ou primitivos passam a ser vistos como produtores de cultura, ainda que essa cultura fosse diferente dos padrões civilizados europeus.

Já no século XX, Pierre Bourdieu, a partir de elementos da sociologia, elenca três termos que apresentam um conceito mais complexo do que o de Edward Burnett Tylor: estrutura, habitus e práticas:

[...] O primeiro diz respeito àquelas regularidades que est]ao associadas a instituições e ambientes sociais (modos de produção e consumo de bens materiais ou abstratos, relações familiares etc.). Tais estruturas produzem habitus, que é uma maneira de ser, um "sistema de disposições duráveis [...] capazes de funcionar como estruturas estruturantes, quer dizer, como princípios de geração e de estruturação de práticas", e que ao longo do tempo acaba por funcionar, inconscientemente, como um princípio ao mesmo tempo arbitrário e interiorizado. As práticas, finalmente, são o resultado dialético entre uma estrutura e um habitus perante uma situação real ou concreta (grifos do autor) (1972 apud CUNHA, 2010, p. 17).

As ciências sociais, portanto, estabelecem definições amplas e completas para o meio ambiente cultural.

Trata-se de um patrimônio ao mesmo tempo material e intelectual, compartilhado e relativamente estável, composto de linguagem, formas de comportamento e de pensamento que atribuem sentido às relações humanas ou divinas, símbolos representativos, técnicas empregadas e objetos produzidos (CUNHA, 2010, p. 17).

A Constituição Federal de 1988 apreende tais compreensões antropológicas e sociológicas de cultura e estabelece que o meio ambiente cultural é o aspecto do direito ambiental que estuda os bens de natureza material e imaterial, portadores de referência à identidade, à ação ou à memória dos diferentes grupos formadores da sociedade brasileira, como, por exemplo: as formas 
de expressão; os modos de criar, fazer e viver; as criações científicas, artísticas e tecnológicas; entre outros, conforme artigo 216 da Constituição Federal.

A tutela do meio ambiente cultural efetiva-se com a preservação destes bens ambientais, sendo dever do Poder Público, com a colaboração da comunidade, promover e proteger o patrimônio cultural brasileiro, por meio de inventários, registros, vigilância, tombamento, desapropriação e outras formas de acautelamento, de acordo com o § 1으 do artigo 216 da Lei Maior.

As formas de acautelamento e preservação do patrimônio cultural brasileiro foram estabelecidas em uma época onde a rede mundial de computadores praticamente não existia. Apesar de bastante complexo e abrangente o conceito de cultura transposto para a Constituição Federal de 88, outros elementos que não foram considerados podem auxiliar o que se pretende abordar no presente trabalho.

Um grupo de intelectuais alemães a partir de 1920, na Universidade de Frankfurt desenvolveu críticas às teorias culturais existentes. Chamada exatamente de Teoria Crítica, a corrente da Escola de Frankfurt considera, entre outros fatores, os produtos e os processos da cultura de massa, denominando-os indústria cultural (ADORNO; HORKHEIMER, Dialética do Esclarecimento, 1985).

Leo Lowenthal, um dos intelectuais menos conhecido deste movimento, esclarece que:

[...] ao produzir uma cultura marcada por "padronização, estereótipos, conservadorismo, falsidade, bens de consumo manipulados", a indústria cultural acabou despolitizando a classe operária e limitando seus horizontes para a percepção de fins políticos e econômicos que, dentro da estrutura opressora e exploradora da sociedade capitalista, poderiam ser alcançados. Ele sustenta que, "sempre que tendências revolucionárias começam a aparecer, são mitigadas e interrompidas por uma falsa satisfação de desejos, como riqueza, aventura, paixão, poder e sensacionalismo em geral". Em suma, a indústria cultural desencoraja as "massas" a pensar além dos limites do presente (apud STOREY, 2015, p. 137).

$\mathrm{Na}$ atual sociedade da informação (FIORILLO, 2015b), em que o armazenamento e a troca de informações se dá em larga escala através da rede mundial de computadores (internet), mister se faz o estudo da tutela do patrimônio cultural no ciberespaço a partir do conceito de cultura de massa. 


\section{Sistema Nacional de Cultura e controle social}

O artigo 216-A da Constituição Brasileira, inserido pela Emenda n. 71/2012, criou o Sistema Nacional de Cultura, que, organizado em regime de colaboração, de forma descentralizada e participativa, tem a finalidade de instituir um processo de gestão e promoção conjunta de políticas públicas de cultura, democráticas e permanentes, pactuadas entre os entes da Federação e a sociedade, tendo por objetivo promover o desenvolvimento humano, social e econômico com pleno exercício dos direitos culturais.

Tal Sistema Nacional de Cultura elegeu como princípio, dentre outros, a democratização dos processos decisórios com participação e controle social, conforme dispõe o artigo 216-A, § 10, $\mathrm{X}$ da $\mathrm{CF}$, in verbis:

"Art. 216-A. O Sistema Nacional de Cultura, organizado em regime de colaboração, de forma descentralizada e participativa, institui um processo de gestão e promoção conjunta de políticas públicas de cultura, democráticas e permanentes, pactuadas entre os entes da Federação e a sociedade, tendo por objetivo promover o desenvolvimento humano, social e econômico com pleno exercício dos direitos culturais. $\S 1$ 으 O Sistema Nacional de Cultura fundamenta-se na política nacional de cultura e nas suas diretrizes, estabelecidas no Plano Nacional de Cultura, e rege-se pelos seguintes princípios: [...] X - democratização dos processos decisórios com participação e controle social; (grifo nosso)".

Destaque-se, desde já, que controle social nada guarda relação com censura. A censura, expressamente proibida pelo artigo $220, \S 2$ 으, CF, é ato estatal praticado por regimes autoritários, antidemocráticos e de exceção. Por outro lado, o controle social é calcado na participação e escolha da sociedade, e não do Estado, sobre o conteúdo que deseja ver veiculado.

A expressão "controle social" está sendo utilizada no presente artigo justamente por estar prevista expressamente em nossa Lei Magna. Na página do Portal da Transparência, onde são disponibilizadas informações sobre os gastos diretos do Governo Federal, encontra-se a seguinte definição de controle social:

"As idéias de participação e controle social estão intimamente relacionadas: por meio da participação na gestão pública, os cidadãos podem intervir na tomada da decisão administrativa, orientando a Administração para que adote medidas que realmente atendam ao interesse público e, ao mesmo tempo, podem exercer controle sobre a ação do Estado, exigindo que o gestor público preste contas de sua atuação" (BRASIL, [200-?]).

Desta feita, a sociedade deve estar presente nas fases de planejamento e execução das políticas públicas não apenas quando houver previsão expressa em texto de lei, mas em toda a gestão pública, tendo em vista que somos um Estado Democrático de Direito. 
O Estado Democrático de Direito transcende a participação popular no processo eletivo já assegurado pela forma republicana de governo. O Estado Democrático de Direito vincula todas as esferas do Estado (não somente os Poderes Executivo e Legislativo) com seus princípios e objetivos.

Aumenta, assim, a participação do povo nos processos decisórios do governo, bem como na fiscalização dos exercícios dos mandatos. E essa fiscalização popular deve sempre visar a garantir a vigência e eficácia dos direitos fundamentais, individuais e coletivos, assegurados constitucionalmente.

Desta forma, o Estado Democrático de Direito é aquele território onde um povo exerce seu poder soberano, tanto por meio de representantes eleitos direta ou indiretamente, quanto pela participação popular direta nas decisões governamentais, sempre respeitando e defendendo os direitos fundamentais, individuais e coletivos, visando a atingir os objetivos prescritos na Lei Fundamental (Constituição) daquele Estado.

O Estado Democrático de Direito brasileiro, como já é cediço na doutrina e jurisprudência, deve guiar-se pelo princípio basilar da dignidade da pessoa humana, norteador de todo sistema jurídico e normativo brasileiro, não somente pelo que determina a Constituição Federal, mas também por diversos tratados e convenções internacionais que o Brasil ratificou, como, por exemplo a Declaração Universal dos Direitos Humanos.

O controle social das mídias objetiva a proteção da dignidade da pessoa humana e a proteção de direitos individuais e coletivos de minorias políticas na medida em que pretende assegurar a participação efetivas dessas minorias ou maiorias excluídas dos espaços de representação. É um dos instrumentos de uma política mais ampla de democratização da mídia.

O debate acerca da democratização da mídia no Brasil já existe há algumas décadas e vem se intensificando. O já mencionado artigo 220, bem como os artigos 221 a 224, todos da Constituição Federal, compõem o Capítulo V e regulamentam a Comunicação Social, trazendo importantes previsões.

Para o presente trabalho serão destacadas apenas algumas dessas garantias. A comunicação social será tratada considerando seus diversos veículos (televisão e rádio, principalmente), e também analisando a rede mundial (internet), como tema principal do trabalho. No entanto, como já foi salientado, na época da promulgação da Constituição Federal, a rede mundial praticamente não existia. E há pouca legislação e poucas pesquisas sobre o tema específico de regulação da rede para proteção do meio ambiente cultural brasileiro. 


\title{
LIMITES CONSTITUCIONAIS AOS MEIOS DE COMUNICAÇÃO SOCIAL
}

O artigo 220, §5으, CF determina: "Os meios de comunicação social não podem, direta ou indiretamente, ser objeto de monopólio ou oligopólio". Este dispositivo pretende proteger a pluralidade de produção de conteúdo, evitando a concentração em poucos produtores. Tal discussão é essencial tendo em vista que, no Brasil, poucas famílias controlam os meios de comunicação no Brasil (FÓRUM NACIONAL pela DEMOCRATIZAÇÃO DA COMUNICAÇÃO, [200-?]).

Ainda em relação à proibição de monopólio e oligopólio da comunicação outro tema merece destaque: a propriedade cruzada. O Intervozes, Coletivo Brasil de Comunicação Social, que tem por objetivo estimular o debate crítico sobre a situação do Direito à Comunicação no Brasil, explica que a propriedade cruzada "(...) é quando o mesmo grupo controla diferentes mídias, como TV, rádios e jornais" (BRANT, 2011).

Exemplo de grande corporação de comunicação que detém propriedades cruzadas é o Grupo Globo que atua em todas as áreas da comunicação: televisão aberta (TV Globo) e fechada (Globosat), rádio (Rádio Globo e CBN), jornais (O Globo) e revistas (Editora Globo), música (Som Livre), cinema (Globo Filmes) e rede mundial de computadores (Globo.com) (GRUPO GLOBO, 2015). O projeto de Lei 6.667/2009, de autoria do Deputado Ivan Valente (PSOL) proíbe a propriedade cruzada e avança:

\begin{abstract}
"Art. 10 Esta lei estabelece limites para a concentração horizontal e vertical dos grupos empresariais de comunicação social, proibindo a propriedade cruzada nos meios de comunicação, e dá outras providências. § 10 Entendese por concentração horizontal um grupo deter várias operadoras da mesma plataforma; por concentração vertical um grupo controlar várias etapas da cadeia produtiva de comunicação - produção, programação, empacotamento e distribuição. E por propriedade cruzada a exploração dos dois serviços pelo mesmo grupo empresarial" (BRASIL, 2009).
\end{abstract}

O projeto de Lei, portanto, proíbe duas formas de propriedade cruzada: horizontal e vertical. $\mathrm{Na}$ horizontal não terá concessão, permissão ou autorização para um mesmo grupo que queira deter várias operadoras da mesma plataforma. É o caso de um grupo que detenha vários canais de televisão. Na vertical não se autoriza que um mesmo grupo controle várias etapas da cadeia produtiva de comunicação. É o caso do exemplo acima mencionado, do Grupo Globo que participa, por exemplo, da produção cinematográfica (Globo Filmes) e musical (Som Livre), ao mesmo tempo em que os distribui e veicula (seja na TV aberta ou Fechada, nas rádios ou na rede mundial de computadores). 
A proibição da propriedade cruzada está, em verdade, limitando os poderes das grandes corporações, tentando evitar o que atualmente presenciamos na comunicação brasileira: monopólios e oligopólios. Tal proibição tem o condão de incentivar a pluralidade de produção e veiculação de conteúdo por diferentes empresas. Além disso, a Constituição Federal, em seu artigo 221, II, estabelece como princípio o estímulo à produção independente que divulgue e promova a cultura nacional e regional.

Outro Projeto de Lei, de autoria da Comissão Mista destinada a consolidar a legislação federal e a regulamentar dispositivos da Constituição Federal, é o de número 5.992/2013.

O mencionado Projeto de Lei define, entre outros parâmetros, o tempo da programação diária dessas emissoras que deverá ser ocupado pela programação regional, e traz elementos para a conceituação de produção independente, tendo em vista o disposto no artigo 221, II e III, CF.

O projeto define produção de caráter regional como sendo a produção cultural, artística e jornalística produzida na região do País onde está localizada a emissora (Norte, Nordeste, CentroOeste, Sudeste ou Sul) e a produção local aquela que é realizada no estado (unidade federativa) da emissora. Outro elemento importante é caracterização de produção independente regional como sendo a desenvolvida por outra empresa localizada na região, que tenha atividade regular e não seja vinculada societariamente, direta ou indiretamente, à emissora (BRASIL, 2013).

Ainda segundo o projeto, pode ser considerada produção cultural, artística e jornalística qualquer produção:

"[...] que abranja conteúdos tais como apresentações musicais, espetáculos de teatro, ópera, circo, dança, dramaturgia, obras de fiç̧ão, de cunho religioso, documentários, animação, noticiosos, debates, mesas-redondas, entrevistas, atualidades, programas de auditório, eventos esportivos" (BRASIL, 2013).

A produção deverá ser dividida igualmente entre regional e local e respeitar os seguintes valores mínimos semanais: localidades com até 500 mil habitantes: 336 minutos; localidades entre 500 mil e 1 milhão de habitantes: 504 minutos; municípios com população entre 1 milhão e 5 milhões de habitantes: 616 minutos; locais com população superior a 5 milhões de habitantes: 840 minutos (BRASIL, 2013).

Note-se que, mesmo essa cota mínima ainda é pequena perto da totalidade da programação, pois a programação semanal soma 10.080 minutos. Nos locais com população superior a 5 milhões de habitantes, faixa onde a cota seria de 840 minutos, isto representa pouco mais de $8 \%$ do total da programação. 
Oportuno esclarecer que o direito à comunicação está sendo aqui considerado como um direito humano, a partir de entendimento de militantes e estudiosos que tem se consolidado ultimamente. Exemplo disso é a Carta de Brasília, confeccionada no Encontro Nacional de Direitos Humanos de 2005, que, entre outros pontos, afirmou:

"[...] Declaramos que: 1. A Comunicação é um direito humano que deve ser tratado no mesmo nível e grau de importância que os demais direitos humanos. O direito humano à comunicação incorpora a inalienável e fundamental liberdade de expressão e o direito à informação, ao acesso pleno e às condições de sua produção, e avança para compreender a garantia de diversidade e pluralidade de meios e conteúdos, a garantia de acesso eqüitativo às tecnologias da informação e da comunicação, a socialização do conhecimento a partir de um regime equilibrado que expresse a diversidade cultural, racial e sexual; além da participação da sociedade na definição de políticas públicas, tais como conselhos de comunicação, conferências nacionais e regionais e locais. A importância do direito humano à comunicação está ligada ao papel da comunicação na construção de identidades, subjetividades e do imaginário da população, bem como na conformação das relações de poder (BRASIL, 2005)".

A partir do entendimento que a comunicação é um direito humano não haveria, portanto, necessidade de regulamentação por legislação infraconstitucional para que ela seja aplicada e protegida, em virtude do que dispõe o artigo 5ㅇ, §1ㅇ, CF, in verbis:

Art. 50 Todos são iguais perante a lei, sem distinção de qualquer natureza, garantindo-se aos brasileiros e aos estrangeiros residentes no País a inviolabilidade do direito à vida, à liberdade, à igualdade, à segurança e à propriedade, nos termos seguintes:

[...] $\S 1$ - - As normas definidoras dos direitos e garantias fundamentais têm aplicação imediata.

Segundo a doutrina constitucionalista mais moderna, como, por exemplo, os neoconstitucionalistas J. J. Gomes Canotilho, Eros Roberto Grau, Flavia Piovesan e Luís Roberto Barroso, o dispositivo em comento assegura que os direitos humanos (ou fundamentais) tenham aplicabilidade imediata. Parece óbvio, mas há doutrinadores que defendem o contrário (FERREIRA FILHO, 2009).

Mesmo sendo desnecessária a regulamentação do direito à comunicação em si, alguns parâmetros para sua aplicação acabam sendo estabelecidos em legislações infraconstitucionais. É por este motivo que foram aqui apontados Leis e Projetos de Leis.

O já mencionado artigo 221 da Constituição Federal assegura como princípio em três dos seus quatro incisos a proteção à cultura nacional e regional, in verbis:

"Art. 221. A produção e a programação das emissoras de rádio e televisão atenderão aos seguintes princípios:

I - Preferência a finalidades educativas, artísticas, culturais e informativas; 
II - Promoção da cultura nacional e regional e estímulo à produção independente que objetive sua divulgação;

III - regionalização da produção cultural, artística e jornalística, conforme percentuais estabelecidos em lei;

IV - Respeito aos valores éticos e sociais da pessoa e da família" (destaque nosso).

Apesar da previsão legal de tais princípios, é de se questionar qual (ou quais) o motivo para que eles não tenham sido aplicados independentemente de regulamentação e nem mesmo regulamentados após quase 30 anos da promulgação da Constituição Federal. A comunicação social (principalmente na internet) não atende aos seus objetivos em virtude do que a Teoria Crítica da Escola de Frankfurt denominou de indústria cultural. Hannah Arendt esclarece:

A sociedade de massa não quer a cultura, mas os lazeres (a diversão) e os artigos oferecidos pela indústria dos lazeres são confortavelmente consumidos pela sociedade como todos os demais objetos de consumo [...]. Servem, como se diz, para passar o tempo, e o tempo vazio que assim é experimentado não constitui o tempo da ociosidade (à moda dos gregos clássicos e da Roma Republicana), ou seja, o tempo no qual estamos livres de toda preocupação e atividade necessárias e, por isso, livres para o mundo e sua cultura; é mais o tempo da sobra, ainda biologicamente determinado pela natureza, aquele que resta após o trabalho e o sono terem cumprido os seus deveres (2000, p. 37).

Para as grandes corporações da comunicação de massa é interessante e confortável manter os dispositivos mencionados não regulamentados a fim de escusar-se de seu cumprimento. A falta de regulação dessas mídias, entretanto, não atende aos anseios da sociedade civil, em especial a organizada, que foram assegurados em nossa Lei Maior.

\section{PATRIMÔNIO CULTURAL BRASILEIRO}

Tratando-se especificamente de cultura, mister se fazem alguns esclarecimentos. Como já foi destacado anteriormente, a cultura protege os bens de natureza material e imaterial, portadores de referência à identidade, à ação ou à memória dos diferentes grupos formadores da sociedade brasileira, conforme artigo 216, caput e incisos da Constituição Federal.

Dúvida pode surgir de quais povos ou grupos a Lei Maior protege o patrimônio cultural. O caput do artigo 216 restringe aos "grupos formadores da sociedade brasileira". O Brasil é um país que recebeu, ao longo de sua História, imigrantes de todos os cantos do mundo, sendo que a maioria (se não todos) dos grupos imigrantes se integrou à sociedade brasileira, formando uma nação altamente miscigenada. 
Aparentemente, então, todos esses povos teriam seus patrimônios culturais protegidos. Não parece ser este o conteúdo disposto na Constituição. O artigo 215, § 1o da Lei Magna prevê, in verbis:

"Art. 215. O Estado garantirá a todos o pleno exercício dos direitos culturais e acesso às fontes da cultura nacional, e apoiará e incentivará a valorização e a difusão das manifestações culturais.

$\S 1$ - - O Estado protegerá as manifestações das culturas populares, indígenas e afro-brasileiras, e das de outros grupos participantes do processo civilizatório nacional".

É possível iniciar o delineamento de quais são os grupos formadores da sociedade brasileira objeto de proteção de seus patrimônios culturais com a leitura do parágrafo 1o do artigo 215 supratranscrito. O dispositivo legal afirma que devem ser protegidas as manifestações das culturas populares, indígenas e afro-brasileiras, "e das de outros grupos participantes do processo civilizatório nacional".

Portanto, os três grupos formadores da sociedade brasileira, cujas manifestações culturais constituem bens ambientais culturais brasileiros são: os indígenas, os afrodescendentes e os "participantes do processo civilizatório nacional".

A justificativa para a inclusão dos indígenas e dos afro-brasileiros é óbvia: os índios são os primeiros habitantes do território brasileiro, a população originária; e os africanos foram sequestrados e trazidos à força para trabalharem como escravos, durante o período do Brasil Colônia.

Para Celso Antonio Pacheco Fiorillo (2000), os demais grupos participantes do processo civilizatório são os imigrantes de diversas regiões do mundo que vieram para o Brasil em grandes quantidades, sendo maior a imigração de uma ou outra nacionalidade em épocas distintas. Boris Fausto (apud FIORILLO, 2000) apresenta como grupos participantes do processo civilizatório nacional os portugueses, alemães, italianos, espanhóis e, em menor quantidade em termos gerais, mas não menos significativos, outros povos como os japoneses, sírio-libaneses e os judeus.

Muito embora seja inegável a contribuição até os dias atuais de todos esses povos imigrantes acima mencionados, parece ser por demais abrangente a inclusão de todos eles na qualidade de grupos participantes do processo civilizatório brasileiro. Porque a História brasileira tem início muito antes da chegada dos portugueses ao Brasil, se considerarmos que o processo civilizatório tem início com os primeiros habitantes de um território. No caso do Brasil, as primeiras ocupações datam de 8.000 a. C., na Lagoa Santa, em Minas Gerais (FIORILLO, 2000, p. 45). 
Com a constante evolução da sociedade, todos os povos que para o Brasil imigraram (e continuam imigrando), poderiam ser considerados pertencentes ao processo civilizatório nacional. Não parece que foi essa a intenção do legislador. O processo civilizatório a que se refere o dispositivo legal é o período referente à ocupação originária do solo brasileiro. Desta forma, quem efetivamente se apropriou do território brasileiro foram os portugueses, que instalaram aqui uma Colônia, da qual Portugal era Metrópole.

A proteção ao patrimônio cultural desses três povos é essencial para resgatar e divulgar as verdadeiras raízes de nosso país. E esse amparo deve se dar em todas as esferas de nossa sociedade, pois os artigos 215 e 216 tratam da proteção a cultura de forma ampla.

\section{PRINCÍPIOS DOS MEIOS DE COMUNICAÇÃO ELETRÔNICA (OU DIGITAL)}

O artigo 221 insere como princípios para a comunicação social, especificamente para a televisão e para o rádio, a proteção e o incentivo à cultura regional e nacional. Reconhecendo que a rede mundial de computadores também deve seguir alguns parâmetros, a Emenda Constitucional n. 36 de 2002 acrescentou ao artigo 222, CF o § 3ำ, que estendeu a obrigação dos princípios do art. 221 aos meios de comunicação eletrônica.

A rede ainda é considerada um ambiente relativamente livre. Para acessar a rede, basta se conectar através de um provedor de acesso. A maioria dos provedores ainda é paga, o que exclui boa parte da população brasileira. Entretanto, tem aumentado o número de pontos ou locais de acesso de forma gratuita, por exemplo, com redes sem fio (wi-fi). E para manter uma página na rede, não é necessário qualquer tipo de autorização, permissão ou concessão, bastando utilizar um serviço de hospedagem gratuito ou pago. Os códigos de acesso à rede são livres:

[...] a Internet desenvolve-se a partir de uma arquitetura informática aberta e de livre acesso desde o início. Os protocolos centrais TCP/IP da Internet, criados em 1973-1978, distribuem-se gratuitamente e à sua fonte de código tem acesso qualquer pesquisador ou técnico.

$[\ldots]$

A última observação que quero fazer sobre a história da Internet é que o acesso a seus códigos - o acesso aos códigos do software que governa a Internet - é, foi e segue sendo aberto, e isso está na base da capacidade de inovação tecnológica constante que se desenvolveu na Internet. Mencionei antes o TCP/IP, mas lembrem também que Unix é um código aberto que permitiu o desenvolvimento da USENET News, a rede alternativa de Internet, e que o World Wide Web é aberto. O Apache - programa de software que hoje maneja mais de dois terços dos servidores World Wide Web do mundo - também é um programa de código aberto. E este é, obviamente, o caso de 
Linux, embora este seja fundamentalmente para as máquinas Unix através das quais funciona a Internet (CASTELLS, 2012, p. 258-261).

Mesmo em relação ao acesso à Internet, embora os códigos estejam disponíveis, em tese, para qualquer cidadão, isso não significa que haja um efetivo acesso. Especialmente em países em desenvolvimento, como o Brasil, onde uma parcela importante da população ainda é analfabeta, ainda há muita exclusão social e, consequentemente, digital. Serão abordados, por isso, outros aspectos da liberdade na comunicação digital.

Como todas as outras liberdades e garantias individuais, nenhuma liberdade é plena e absoluta. Em poucas palavras, a liberdade é a faculdade que uma pessoa ou ente possui de praticar qualquer ato. Essa liberdade, no entanto, nunca é plena, pois é autorizado ao Estado estabelecer limites às atitudes das pessoas, quando julgar justa ou necessária.

O problema central da liberdade é detectar se esses limites impostos são realmente justos e/ou necessários. Nesse sentido, afirma José Afonso da Silva: "Liberdade opõe-se a autoritarismo, à deformação da autoridade; não porém, à autoridade legítima. Esta provém do exercício da liberdade, mediante o consentimento popular" (1994).

A liberdade, para a cultura ocidental, está intrinsecamente ligada ao conceito de democracia, tendo em vista que "todo poder emana do povo", conforme artigo 1ํ, parágrafo único da $\mathrm{CF} / 88$, inclusive o poder que limita relativamente as liberdades. Deveria, portanto, a própria sociedade regulamentar as condutas a serem seguidas. Entre as liberdades de pensamento, podem ser citadas a liberdade de expressão e a liberdade de crença religiosa, asseguradas no artigo 5ㅇ, IX e VI, CF, respectivamente.

A rede mundial de computadores, desta forma, caracteriza-se como um ambiente ainda relativamente democrático. No entanto, a discussão do agora aprovado Marco Civil da Internet, Lei n. 12.965/2014 trouxe algumas reflexões importantes sobre essa liberdade. O maior exemplo disso foi a garantia da chamada neutralidade da rede como princípio, conforme o art. 3ํ, IV da referida Lei: "A disciplina do uso da internet no Brasil tem os seguintes princípios: (...) IV - preservação e garantia da neutralidade de rede".

O Marco Civil, em Seção própria (Capítulo III, Seção I - Da neutralidade da Rede), no artigo 9o, disciplina a neutralidade:

"Art. 9o. O responsável pela transmissão, comutação ou roteamento tem o dever de tratar de forma isonômica quaisquer pacotes de dados, sem distinção por conteúdo, origem e destino, serviço, terminal ou aplicação".

Celso Antonio Pacheco Fiorillo explica objetivamente o que é a neutralidade: 
"O que pretende aludido princípio é assegurar que todas as informações que trafegam na rede devam ser tratadas da mesma forma, navegando à mesma velocidade, sendo referido princípio que garantiria o livre acesso a qualquer tipo de informação na rede" (2015a, p. 38-39).

A neutralidade assegurou, portanto, que a transmissão de dados seja isonômica e garanta, por exemplo, que sejam acessados de forma igual ou semelhante a página de uma grande corporação da área alimentícia e o blog do seu vizinho sobre culinária.

Apesar desta grande conquista, a discussão do projeto de Lei despertou a possibilidade de haver lobby das grandes corporações das telecomunicações no Brasil (Vivo, Oi, Claro, Tim), que se posicionaram de forma contrária à neutralidade.

Uma emenda apresentada pelo PMDB (que não foi aprovada) excluía os serviços de internet da regra geral da neutralidade e liberava a contratação de pacotes com condições especiais para quem quiser conteúdo diferenciado - só redes sociais, só vídeos. O então deputado Eduardo Cunha defendeu com unhas e dentes a liberação de pacotes de dados diferenciados, assegurando que a neutralidade encareceria o serviço de internet para todos (PMDB, 2014).

O Decreto n. 8.771/16 regulamentou o Marco Civil da Internet e manteve a neutralidade da rede prevista no Marco, excepcionando a discriminação ou degradação de dados somente nas hipóteses de falta de requisitos técnicos indispensáveis à prestação adequada de serviços e aplicações ou da priorização de serviços de emergência, como, por exemplo, catástrofes naturais, conforme artigo 4음 do referido Decreto.

Outro ponto importante referente à neutralidade mantido pelo Decreto foi a proibição da franquia zero ou zero rating. $\mathrm{O}$ artigo 9o estabeleceu:

Art. 9o Ficam vedadas condutas unilaterais ou acordos entre o responsável pela transmissão, pela comutação ou pelo roteamento e os provedores de aplicação que:

I - Comprometam o caráter público e irrestrito do acesso à internet e os fundamentos, os princípios e os objetivos do uso da internet no País;

II - Priorizem pacotes de dados em razão de arranjos comerciais; ou

III - Privilegiem aplicações ofertadas pelo próprio responsável pela transmissão, pela comutação ou pelo roteamento ou por empresas integrantes de seu grupo econômico.

As ofertas de acesso gratuito ou franquia zero a determinados aplicativos ou redes sociais, como Whatsapp ou Facebook, pelos responsáveis pela transmissão de dados, como as operadoras de telefonia celular foram proibidas. A operadora Claro, por exemplo, oferta em sua página na rede uma promoção, garantindo Whatsapp à vontade sem descontar da sua internet (PROMO, [201-? ]). 
Apesar de um aparente benefício ao consumidor, a franquia zero trata de forma desigual aplicativos ou redes sociais que têm maior capacidade econômica daqueles que não têm. Rafael Zanatta, advogado e pesquisador do Idec - Instituto de Defesa do Consumidor - esclarece:

Isso traz um grande impacto à inovação. Os aplicativos que hoje fazem sucesso nasceram como startups e conquistaram seu lugar no mercado porque são bons. Num cenário de privilégios a determinadas aplicações, criase uma barreira à entrada de novas empresas que podem ser melhores do que as já estabelecidas (INSTITUTO DE DEFESA DO CONSUMIDOR, 2016).

Apesar de toda a participação da sociedade civil no debate, o fato é que um princípio estrutural do Marco Civil - a neutralidade - esteve em perigo durante sua tramitação, deixando transparecer que, muitas vezes, a vontade da sociedade não é ouvida por seus representantes no Poder Legislativo.

Além disso, a proibição de franquia zero (zero rating), em vigor no Brasil desde junho de 2016, está sendo desrespeitada pelas empresas de comunicação, como se comprova com a oferta em vigor de promoções de operadoras de telefonia de celular, como a mencionadas linhas atrás.

\section{REGULAÇÃO DA REDE MUNDIAL DE COMPUTADORES}

Para que se mantenha essa liberdade relativa existente na rede, é preciso analisar se há necessidade de uma maior regulação, além da já prevista na Constituição Federal de 88, que estendeu a obrigatoriedade de os meios de comunicação social eletrônica, independentemente da tecnologia utilizada para a prestação do serviço, observarem os princípios enunciados no art. 221, CF.

Inicialmente, é possível partir de um primeiro ponto. Assim como todos os bens ambientais, o espectro eletromagnético não é infinito. A transmissão de dados nos mais diferentes meios de comunicação ( $t v$, rádio, telefone celular ou internet) trafegam, de alguma forma, pelo espectro eletromagnético. E esse espectro tem sido considerado, portanto, um bem escasso (HORVITZ apud BRANT, 2007). João Brant destaca:

"Por décadas, essa foi a principal razão para a regulação da radiodifusão rádio e televisão - em todo o mundo: o espectro é um bem escasso, não há lugar para todos, portanto licenças são necessárias; do contrário, há uma tendência à 'super-utilização' e o caos passa a imperar. Como se trata de um bem público, cabe ao Estado alocá-las. Parece haver lógica nesse raciocínio, mas daí surgiu um problema. Se, por questões técnicas, o governo é quem diz quem transmite e quem não transmite, as regras de administração desse gargalo tornaram-se aspecto-chave para determinar quem tem voz no espaço público. No entanto, essas regras de administração não são baseadas apenas em critérios técnicos, mas também, como veremos adiante, em 
critérios políticos e econômicos - até porque não há critérios técnicos que por si só sejam suficientes para determinar quem deve ocupar tal espaço. A decisão passa a ser necessariamente sustentada em critérios mais amplos. Como não há espaço para todos, e cabe ao governo dizer quem pode falar, a decisão de quem usa o espectro (e em que condições) é necessariamente uma interferência dos governos na liberdade de expressão. Controlar o espectro é controlar a possibilidade de se expressar. Ou, como aponta Noam (1997, p. 463), 'um esquema de licenciamento, independentemente da forma como é concebido, é uma séria restrição à expressão'. Isso coloca uma enorme responsabilidade nas mãos dos responsáveis pelas políticas de uso do espectro, já que essas definições são determinantes do grau de pluralidade e diversidade que será encontrado na comunicação de um país. E se pluralidade e diversidade de conteúdo são condições indispensáveis à realização da democracia, como discutiremos neste texto, a política para uso do espectro é uma variável que interfere diretamente na democracia de cada país" (2007).

Elementos importantes podem ser destacados deste trecho do artigo de Brant. Para quem repudia qualquer forma de controle da mídia, apresenta-se uma constatação: já existe certa regulação com as concessões, permissões e autorizações para as empresas de comunicação no Brasil.

Os critérios usados para essa regulação não são necessariamente democráticos, pois não respeitam a pluralidade e a diversidade de um país com mais de 200 milhões de habitantes e com 8.515.767,049 quilômetros quadrados $\left(\mathrm{km}^{2}\right)$ de extensão territorial (ÁREA, 2013). Como já salientado, poucas famílias controlam os meios de comunicação de massa nas diferentes formas de atuação: televisão, rádio, imprensa escrita, telecomunicações e, mais recentemente, rede mundial de computadores.

Em um primeiro momento, as plataformas de comunicação eletrônica, em especial a rede mundial de computadores não foram considerados ambientes escassos e, portanto, não haveria necessidade de regulação. Não parece, todavia, ser este entendimento condizente com a realidade (BRANT, 2007).

“(...) O potencial democratizante possibilitado pela evolução tecnológica tem esbarrado em interesses comerciais. Por conta de características das economias de rede, em uma típica dinâmica capitalista, interesses privados buscam criar novos gargalos para manter a escassez. Como consequência, o interesse público é colocado em segundo plano, e surgem novas restrições à pluralidade e à diversidade. Esses novos gargalos tornam-se ainda mais relevantes quando a comunicação de massa que utiliza o espectro radioelétrico deixa de ser apenas o rádio e a televisão, e passa a englobar também diversos serviços que utilizam a internet e o protocolo IP. Já é certo que, daqui a alguns anos, teremos boa parte do conteúdo dos meios de comunicação trafegando sobre IP. Neste cenário, Wi-Fi, Wi-Max e redes mesh, por exemplo, passam a ser tecnologias altamente relevantes para a 
comunicação de massa. Portanto, não apenas as políticas para uso do espectro reservado à radiodifusão, mas toda a faixa de frequências que tem que ver com algum desses serviços passa a interferir na pluralidade e na diversidade de conteúdo - e consequentemente, na democracia" (BRANT, 2007).

Como exemplo da manutenção da escassez nos meios eletrônicos de comunicação pode ser citada a implantação da TV digital no Brasil, pois havia possibilidade de ampliação do número de emissoras, no entanto foram apenas mantidas as emissoras antigas da plataforma analógica. Cada uma dessas emissoras recebeu o espaço que poderia ser ocupado por elas e, pelo menos, mais cinco novas emissoras (BRANT, 2007). Nota-se a manutenção desta lógica de mercado em um ambiente que poderia vir a ser muito mais democrático.

A regulação do espectro feita pelo Estado para definir quem usa qual frequência (tradicionalmente usada para rádio e tv) agora deve considerar também a transmissão de dados pela rede. O que se percebe é uma tendência a se manter a mesma forma de regulação pelo Estado, chamada de modelo administrativo por Noam (apud BRANT, 2007), com a concentração das concessões, permissões ou autorizações nas mãos de poucos conglomerados da comunicação.

\section{REGULAÇÃO DO ESPECTRO ELETROMAGNÉTICO E REGULAÇÃO DE CONTEÚDO}

Conforme se pode depreender da transcrição supra do artigo de João Brant, há dois aspectos na regulação da mídia digital: a regulação do espectro eletromagnético e a possibilidade de regulação de conteúdo. Quanto mais atores existirem no cenário da comunicação, mais pluralidade, mais diversidade e, portanto, mais democracia haverá. Em verdade, o que se quer demonstrar aqui neste trabalho é que a pulverização das mídias é essencial em um país democrático.

Para tentar solucionar a questão da regulação do espectro e torná-lo mais acessível a um maior número possível de pessoas, uma sugestão é adotar o sistema de espectro aberto, que prevê o uso cooperativo de faixas de frequência sem a necessidade de autorização estatal. Em algumas faixas do espectro já é utilizado o espectro aberto, como, por exemplo, o Wi-Fi (rede sem fio) e Bluetooth (BRANT, 2007).

O espectro aberto pode ser uma alternativa ao menos para pessoas físicas e, em especial, para as classes menos favorecidas. É certo que muitas cidades no mundo têm disponibilizado o acesso Wi-Fi em locais públicos, como praças ou dentro de transporte públicos, mas, em grande parte, ainda é insipiente e com baixa transferência de dados e pouca velocidade, que dificilmente permite que o usuário baixe, por exemplo, um filme ou documentário para estudo ou lazer. 
Caso não seja totalmente viável, é possível pensar em sistemas mistos. Por exemplo, o atual (modelo administrativo) e o de espectro aberto. Esse sistema misto pode, inclusive, ser uma transição para o de espectro aberto em definitivo.

Finalmente, em relação ao controle social (ou regulação) dos conteúdos transmitidos pela rede mundial de computadores para a tutela do meio ambiente cultural, já foram indicados elementos para confirmar a sua necessidade, tendo em vista que a pluralidade e a diversidade, especialmente em um país miscigenado como é o Brasil são imprescindíveis para a construção de uma sociedade tolerante e democrática.

Merece ser transcrito o seguinte trecho do artigo de Gustavo Gindre:

“(...) O conceito ampliado de cultura abarcaria não apenas o conhecimento produzido por dada civilização, mas também o conjunto dos suportes que permitem tornar perene esse conhecimento. E por suporte entendamos um largo espectro material que passa por arquitetura, culinária, vestuário, utensílios e equipamentos usados na produção etc. Já o conceito ampliado de comunicação permite dar conta de todo o conjunto de trocas culturais efetuadas no interior de uma civilização. Assim, é possível dizer que tudo comunica! Como é fácil perceber por esta breve definição, cultura e comunicação fazem parte de um todo inextricável e são parte do mesmo processo de construção da humanidade por si mesma. Contudo, as civilizações letradas especializaram o processo de comunicação, reservando uma parte específica de seu tempo para produzir instrumentos que tenham explicitamente a função de armazenar e transmitir conhecimentos. No século XX, com o desenvolvimento dos modernos meios de comunicação de massa, a atividade da comunicação passou a representar um papel cada vez mais importante nas sociedades capitalistas. Esta centralidade no plano simbólico teve repercussões na infra-estrutura produtiva. Assim, os processos comunicacionais de massa passaram a envolver um montante crescente de recursos, tornando-se, no começo do século XXI (e com o surgimento da comunicação digitalizada), uma das principais atividades econômicas no interior do capitalismo. Quer seja pela sua importância cultural (organizando hábitos e costumes e estruturando comportamentos e gostos), quer seja por seu impacto econômico, a comunicação se torna uma atividade essencial da civilização contemporânea. Ocorre que essa "nova" comunicação tem como uma de suas características fundamentais a mediação, ou seja, ela não é mais feita de forma interpessoal. Tal mudança nos coloca diante de um paradoxo. De um lado, temos o fato de que comunicar é uma das características fundantes do ser humano. Despossuir um indivíduo de sua capacidade de se comunicar com os outros de sua espécie é despossuí-lo de sua própria humanidade. Por outro lado, e cada vez mais, a comunicação é exercida por grandes e especializadas estruturas produtivas que funcionam como mediadores entre a produção e a recepção do conhecimento produzido. Democratizar os processos comunicacionais passa a ser, portanto, uma das principais tarefas da humanidade no século XXI. Em grande medida, será o sucesso ou não desta tarefa histórica que medirá o grau de democracia das nossas sociedades" (2007). 
No trecho supra transcrito, o autor relaciona cultura e comunicação, esclarecendo que a divulgação da cultura é essencial para sua proteção. Tanto a cultura quanto a comunicação, como direitos humanos e fundamentais que são, não podem ser transformados em mercadoria. Nesse mesmo sentido:

"Adotar a pluralidade e diversidade de conteúdo como objetivos de um sistema de comunicação significa assumir que este sistema deve estar a serviço do interesse público. Sendo a comunicação muito mais do que uma atividade comercial, ela não pode ser sujeita apenas à regulação econômica" (BRANT, 2007).

A fim de se garantir a tutela do meio ambiente cultural na rede mundial de computadores são necessárias, portanto ambas as formas de regulação: a do espectro eletromagnético e do conteúdo arquivado e transmitido na e pela rede. O ideal seria que ambos pudessem ser em conjunto, tendo em vista que a regulação do conteúdo pode ser consequência da regulação de quais atores detêm o espectro eletromagnético.

A regulação do espectro para utilização da rede deve ser discutida juntamente com a regulação do espectro para os demais meios de comunicação que dele se utilizam: a televisão e o rádio. Aproveitar toda a discussão já existente sobre regulação das concessões, permissões e autorizações para tv e rádio pode favorecer a possibilidade de uma transformação sem precedentes na comunicação brasileira.

A Frente Nacional por Políticas Democráticas de Comunicação atuou na finalização dos trabalhos da Assembleia Nacional Constituinte, contribuindo para a garantia do já mencionado Capítulo V da Constituição Federal que trata da comunicação no Brasil (arts. 220 a 224). Tais dispositivos, no entanto, não foram suficientes para a efetivação da democratização da mídia.

A Frente transforma-se em um movimento social, chamado de Fórum Nacional pela Democratização da Mídia (FNDM) em 1991 e, posteriormente, em 1995, em associação civil com o mesmo nome, sendo a principal entidade atuante na luta pela democratização das mídias no Brasil. Um Projeto de Lei de Iniciativa Popular da Comunicação Social Eletrônica, conhecido como Projeto de Lei da Mídia Democrática, que regulamenta os arts. 5, 21, 220, 221, 222 e 223 da Constituição Federal foi proposto a partir das Conferências e Seminários organizados pelo Fórum (PROJETO, [200-?]).

Especificamente em relação à regulação do espectro eletromagnético, e considerando que as plataformas de tv, rádio e rede mundial de computadores tendem a uma interligação sem volta, uma das propostas do Projeto é a de aumentar o número de emissoras públicas, conforme artigo 50 (PROJETO, [200-? ]): 
"Artigo 5o - As outorgas para os serviços de comunicação social eletrônicas e dividem nos seguintes sistemas:

I. Sistema público: compreende as emissoras de caráter público ou associativo-comunitário, geridas de maneira participativa, a partir da possibilidade de acesso dos cidadãos a suas estruturas dirigentes e submetidas a regras democráticas de gestão, desde que sua finalidade principal não seja a transmissão de atos dos poderes Executivo, Legislativo e Judiciário;

II. Sistema privado: abrange as emissoras de propriedade de entidades privadas em que a natureza institucional e o formato de gestão sejam restritos, sejam estas entidades de finalidade lucrativa ou não;

III. Sistema estatal: abrange as emissoras cuja finalidade principal seja a transmissão de atos dos poderes Executivo, Legislativo e Judiciário e aquelas controladas por instituições públicas vinculadas aos poderes do Estado nas três esferas da Federação que não atendam aos requisitos de gestão definidos para o sistema público.

$\S 1$ o - Pelo menos $33 \%$ dos canais ou capacidade de espectro destinados à televisão terrestre e rádio serão reservados ao sistema público, sendo pelo menos 50\% deles para os serviços prestados por entes de caráter associativo-comunitário.

$\S 20$ - Cabe ao Poder Executivo assegurar que os serviços prestados por emissoras integrantes do Sistema Público mantidas ou vinculadas ao Poder Público cheguem a pelo menos $80 \%$ dos municípios brasileiros.

$\S 3$ - As emissoras integrantes do sistema público mantidas ou vinculadas ao Poder Público deverão ter em seu modelo institucional um órgão curador composto em sua maioria por integrantes da sociedade civil, com diversidade de representação e indicação pelos pares. Essa instância deve participar das discussões e das decisões estratégicas da emissora e acompanhar seu desempenho, zelando, entre outras coisas, pela qualidade da programação e independência e autonomia nas decisões editoriais".

Percebe-se que o projeto se preocupa muito com a participação social em vários aspectos, em especial nos sistemas públicos, que contariam com integrantes da sociedade civil na gestão e em um conselho curador que participaria das decisões e da fiscalização das emissoras públicas. E no tocante à regulação de conteúdo, o Projeto traz diversas regulamentações, a maioria na forma de conteúdo mínimo (cotas), como, por exemplo, os artigos 19 e 20, in verbis:

Artigo 19 - Com vistas à promoção da diversidade regional, as emissoras de televisão terrestre deverão respeitar as seguintes exigências: I. As emissoras afiliadas a uma rede deverão ocupar no mínimo 30\% de sua grade veiculada entre $7 \mathrm{~h}$ e Oh com produção cultural, artística e jornalística regional, sendo pelo menos sete horas por semana em horário nobre. II. As emissoras com outorgas locais devem ocupar no mínimo $70 \%$ de sua grade com produção regional.

Artigo 20 - As emissoras de televisão terrestre deverão veicular no horário nobre o mínimo de $10 \%$ de programação produzida por produtora brasileira independente, sendo no mínimo 50\% desse tipo de conteúdo realizado na própria área de mercado da emissora. 
Este Projeto da Projeto de Lei de Iniciativa Popular da Comunicação Social Eletrônica supera e muito o percentual sugerido pelo Projeto de Lei 5.992/2013 já mencionado, passando de cerca de $8 \%$ (nas localidades com maior número de habitantes) para 30\% (indiferentemente de número de habitantes) o percentual mínimo de programação regional para emissoras afiliadas e $70 \%$ para as emissoras com outorgas locais.

Para fiscalizar os percentuais de conteúdos regionais no rádio e na televisão a sistemática é mais simples: controlar o número de minutos ou com uma soma já definida, como no Projeto de Lei 5.992/2013 ou com porcentagem, como no Projeto de Lei da Comunicação Social Eletrônica. O problema é transpor um percentual para a rede mundial de computadores. E para quais páginas da rede.

O debate sobre a regulação de conteúdos ganhou novos contornos a partir das Manifestações de Junho de 2013, conhecidas também como Jornadas de Junho de 2013. Com dinâmica parecida com manifestações de rua que estavam ocorrendo em muitos lugares do mundo, como a Primavera Árabe, Occupy Wall Street e o Movimento 3M na Espanha, entre outros, as Manifestações de Junho iniciaram-se com a pauta de gratuidade no transporte público, após o aumento dessas tarifas em várias cidades brasileiras e levou às ruas milhões de manifestantes.

A cobertura da imprensa escrita, televisiva e digital dos grandes conglomerados de comunicação de massa no Brasil foi alterando seu discurso durante o período das manifestações. As primeiras análises da grande imprensa e da sociedade acerca das Manifestações foram de repúdio, generalizando todos os manifestantes como sendo vândalos e criminosos, sem direito a protestar, que estavam interrompendo o trânsito nas maiores avenidas do país e, consequentemente, atrapalhando a vida de milhares de pessoas.

Após a constatação de que muitos daqueles que participaram dos movimentos não eram vândalos e que, entre as pessoas que sofreram violenta e desnecessária repressão policial, estavam, inclusive, jornalistas, fotógrafos, câmeras que trabalham para as imprensas de massa, estes últimos mudaram a pauta e passaram a apoiar as manifestações (INTERVOZES, 2014). Isso se deu, inclusive, pela péssima repercussão que gerou na imprensa internacional: uma democracia como o Brasil tentando abafar movimentos populares legítimos, que reinvidicavam melhorias para a sociedade.

Ao mesmo tempo em que a rede mundial de computadores foi o meio de comunicação utilizado para conclamar as pessoas a participarem das manifestações, também foi utilizado pela imprensa de massa que atua nas plataformas tradicionais (rádio e televisão) e na internet para 
trazer informações parciais e falaciosas dos protestos. O Coletivo Intervozes elaborou uma pesquisa sobre a cobertura dos jornais O Estado de S. Paulo, Folha de S. Paulo e O Globo na mídia digital (INTERVOZES, 2014).

A mudança radical de posicionamento na cobertura das Jornadas de Junho de 2013 pelos grandes conglomerados de comunicação de massa no Brasil corrobora para a proposta do presente trabalho de que deve haver um controle de conteúdo das mídias de massa, inclusive as que atuam na rede mundial de computadores no Brasil.

Algumas

questões precisam ser mais bem estudadas. Não há controle sobre a totalidade de conteúdo que é armazenado na rede. E as dificuldades se aprofundam, já que, se não há um local onde tudo fica armazenado, sendo praticamente inviável determinar porcentagens de conteúdo a toda e qualquer página da internet, indiscriminadamente.

Hipótese mais coerente pode ser o controle social nas páginas brasileiras de conteúdo, em especial, as que derivam ou reproduzem conteúdo televisivo e/ou radiofônico. Assim, as grandes corporações da comunicação seriam impelidas a reservar uma parte do conteúdo divulgado que faça referência ao meio ambiente cultural brasileiro.

E, no caso de desrespeito, deve ser previsto um sistema de sanções, desde advertências e multas até a retirada da página da rede. Ou mesmo com a cassação das outorgas nas outras mídias pertencentes ao mesmo grupo (tv ou rádio), tendo em vista que a convergência digital entre as diferentes plataformas já é uma realidade que tende a crescer cada vez mais. Tal sistema de fiscalização deverá ser sofisticado e acompanhar a inserção de conteúdo nas páginas de forma tão rápida quanto possível.

\section{CONSIDERAÇÕES FINAIS}

A expressão "controle social" pode gerar alguma confusão para quem não tem intimidade com a comunicação, tendo em vista que, muitas vezes, as próprias corporações de comunicação afirmam, propositadamente, que controle social é censura e que desrespeita a liberdade de expressão. Muito longe disso, o controle social é a participação democrática da sociedade em todas as etapas de atuação da administração pública ou privada que envolvam direitos da coletividade. Inclusive quando da outorga de concessões, permissões e autorizações para exploração de qualquer serviço de radiodifusão de sons e imagens para a iniciativa privada.

Embora o monopólio e o oligopólio sejam proibidos na área de comunicação, o fato é que existem pouquíssimas grupos de empresas que dominam esse mercado, como grupos Globo, 
Record, SBT e Bandeirantes. Além disso, há as propriedades cruzadas com concentrações horizontal e vertical. A horizontal ocorre quando um mesmo grupo detém várias operadoras na mesma plataforma como, por exemplo, um mesmo grupo que tenha vários canais na televisão aberta. A vertical acontece se um mesmo grupo controla várias etapas da cadeia produtiva da comunicação, por exemplo, produz-se um filme e ele é veiculado em canal aberto de tv pertencente ao próprio grupo. O projeto de Lei 6.667/2009 quer proibir ambas as formas de propriedade cruzada.

Alguns Projetos de Lei pretendem regulamentar os incisos II e III do art. 221, CF, estabelecendo tempos mínimos para programação regional e local nas tvs abertas. No PL 5.992/2013, o valor máximo, no entanto é de pouco mais de 8\% da programação total.

Note-se que os incisos I, II e III (e também o IV indiretamente) do art. 221 da Constituição Federal trazem a proteção da cultura. O patrimônio cultural contempla, entre outros, as formas de expressão, os modos de criar, fazer e viver e as criações artísticas, científicas e tecnológicas que tragam referências à identidade, ação ou memória dos grupos formadores da sociedade brasileira, participantes do processo civilizatório nacional (arts. 216 e 215, § 1으, CF).

Por ter recebido e continuar recebendo muitos imigrantes, poderia ser por demais extensiva a interpretação de quais são esses grupos participantes do processo civilizatório nacional. Assim, considerou-se no presente trabalho apenas portugueses, população indígena e afrodescendentes. É certo que o povo português, como povo dominante que impôs sua cultura sobre os outros povos conquistados, não necessitam tanto de proteção. No entanto, a população indígena que é uma pequena minoria na população brasileira e o povo negro que é uma maioria excluída necessitam de muita proteção. Essa é a verdadeira base social, as raízes do povo brasileiro, que precisa ainda vencer o preconceito e o racismo contra essas duas populações.

A EC 36/2002 determinou que os mesmos princípios do art. 221 (destinados ao rádio e à tv) sejam observados por todos os meios de comunicação social eletrônica. Com a convergência tecnológica, as plataformas de comunicação serão cada vez mais integradas, tendo sido muito acertada a inclusão do legislador.

A rede mundial de computadores como ambiente relativamente livre esteve ameaçada inclusive na elaboração do Marco Civil da Internet (Lei n. 12.965/2014). Mesmo assim a Lei conseguiu assegurar a neutralidade da rede, que manteve o tratamento isonômico entre as mais diferentes páginas. Esse perigo, entretanto, deixou claro que a indústria das teles (conglomerados 
de telecomunicações) não estão dispostas a perder espaço, nem de perder a possibilidade de explorar ainda mais o mercado da rede, cobrando a mais por pacotes com mais dados.

São dois os tipos de regulação dos meios de comunicação: do espectro eletromagnético e de conteúdo. O espectro eletromagnético para o meio eletrônico, inicialmente tido como ambiente que não necessitaria de regulamentação, divide agora o espectro com o rádio e a tv e, com a grande tendência da convergência digital dessas e de outras diferentes plataformas, essa regulação passa a ser discutida.

Na tentativa de manter o propósito de ambiente livre, uma solução possível é o espectro aberto, liberando o sinal de internet para todos, sem passar pelo intermediador que precisa de outorga do Estado (as teles).

A outra face da regulação é a de conteúdo. O controle social de conteúdo da mídia é essencial para que todos os incisos do já mencionado art. 221, CF sejam cumpridos e que nossa comunicação seja minimamente democrática.

Não é possível pensar em efetivar a democracia sem pluralidade, diversidade e proteção das minorias políticas que não têm acesso às esferas de poder. A comunicação, como já afirmado algumas vezes, é um dos principais campos de poder em nossa sociedade da informação. A tutela do meio ambiente cultural na rede é, portanto, essencial para proteção das raízes e da ancestralidade nacionais.

Cultura e comunicação, como direitos humanos que são, merecem total atenção de nossa sociedade e de nosso Estado. Especialmente nesse momento que o país vive em que garantias históricas nos direitos humanos (como, por exemplo, o Estatuto da Família que pretende reduzir o conceito de família ao casal heterossexual: homem e mulher) estão correndo risco de graves violações.

Os modos de criar, fazer e viver dos povos não são mais transmitidos oralmente de geração em geração; temos agora mediadores, como explicou Gustavo Gendre: "[...] e cada vez mais, a comunicação é exercida por grandes e especializadas estruturas produtivas que funcionam como mediadores entre a produção e a recepção do conhecimento produzido" (2007). E, em uma economia capitalista neoliberal, grandes estruturas transformam tudo o que podem em mercadoria.

Assim, inserir a sociedade, em especial as populações indígena e negra, nos processos de produção e distribuição de suas próprias culturas através dos meios de comunicação é uma forma de tentar minimizar o impacto de séculos de abandono dessas culturas. 
Fruto do Fórum Nacional pela Democratização da Mídia, o Projeto de Lei de Iniciativa Popular da Comunicação Social Eletrônica sugere o aumento de sistemas públicos de comunicação, com cotas de outorgas para emissoras públicas. Tal Projeto de Lei também traz programações mínimas de produção regional e de produção independente.

Percebe-se, no entanto, que ambos os projetos de Lei (PL 5.992/2003 e o de Iniciativa Popular) asseguram programação mínima para produção cultural, artística e jornalística. Nenhum deles ressalta a necessidade de produção do patrimônio cultural especificamente das minorias políticas (indígenas e negros). E nem mesmo garante a participação desses grupos nos processos decisórios.

Para regular o conteúdo de rádio e tv a fim de que eles respeitem os princípios constitucionais do art. 221, bem como a dignidade da pessoa humana (art. 1o, III, CF) e outros direitos e garantias individuais e coletivas prevista na Constituição Federal, enfrenta-se uma resistência enorme.

A regulação da rede mundial de computadores, mesmo sendo como a sugestão do presente trabalho, apenas em relação às páginas de conteúdo das grandes corporações da mídia que se inseriram na rede, redundará em uma resistência maior ainda.

É necessário, portanto, desmistificar a suposta liberdade que existe na internet que, atualmente, é a liberdade de mercado onde tudo se transforma em mercadoria, até mesmo os dados de quem faz uma simples pesquisa sobre um produto no buscador Google.

A rede mundial de computadores, como ambiente ainda relativamente livre e com grande potencial transformador e democrático, precisa ser regulado. E a tutela dos povos indígena e negro nessa mídia é uma maneira efetiva de se garantir a proteção do patrimônio cultural brasileiro.

\section{REFERÊNCIAS BIBLIOGRÁFICAS}

ADORNO, Theodor L. W.; HORKHEIMER, Max. Dialética do Esclarecimento. Tradução: Guido Antonio de Almeida, 1985.

ÁREA territorial do Brasil aumenta em $890 \mathrm{Km}^{2}$ após atualização do IBGE. 23 jan. 2013. Disponível em <http://www.ebc.com.br/noticias/brasil/2013/01/area-territorial-do-brasil-teve-incrementode-001-em-atualizacao-divulgada>. Acesso em: 25 out. 2015.

ARENDT, HANNAH. Entre o passado e o futuro. Tradução: Mauro W. Barbosa de Almeida. 5a ed. V. 64. São Paulo: Perspectiva, 2000 (Coleção Debates). 
BOURDIEU, Pierre. Esquisse d'une théorie de la pratique. Genebra: Librarie Droz, 1972 apud CUNHA, Newton. Cultura e ação cultural: uma contribuição a sua história e conceitos. São Paulo: Edições SESC SP, 2010.

BRANT, João. Novos modelos, novas possibilidades, novos riscos: como as mudanças na gestão do espectro podem impactar a pluralidade e a diversidade de conteúdo. In: SILVEIRA, Sérgio Amadeu et al. Comunicação Digital e a construção dos commons. São Paulo: Fundação Perseu Abramo, 2007, p. 91-127.

Por que e como se limita a propriedade cruzada. 31 jan. 2011. Disponível em <http://www.intervozes.org.br/direitoacomunicacao/?p=25290>. Acesso em: 15 out. 2015.

BRASIL. Câmara dos Deputados. Comissão de Direitos Humanos e Minorias. 18 ago. 2005. Carta de Brasília. Disponível em: <http://www2.camara.leg.br/atividade-legislativa/comissoes/comissoespermanentes/cdhm/noticias/endh_cartabrasilia>. Acesso em: 12 out. 2015.

Câmara dos Deputados. Projeto de Lei 5.992/2013. 2013. Disponível em <http://www.camara.gov.br/proposicoesWeb/prop_mostrarintegra;jsessionid=7182700178A49EA OF58C522001319839. proposicoesWeb1?codteor $=1110733 \&$ filename $=P L+5992 / 2013>$. Acesso: 1 o out. 2015.

Câmara dos Deputados. Projeto de Lei 6.667/2009. 2009. Disponível em <http://www.camara.gov.br/proposicoesWeb/prop_mostrarintegra;jsessionid=4EC709A367FF40D 97961ABC8C93DDB6D. proposicoesWeb2?codteor $=727351 \&$ filename $=P L+6667 / 2009>$. Acesso em 12 out. 2015. 1988.

Constituição (1988). Constituição da República Federativa do Brasil. Brasília, DF: Senado,

Constituição (1988). Emenda constitucional n. 9 36, de 28 de maio de 2002. Disponível em $<$ http://www.planalto.gov.br/ccivil_03/constituicao/emendas/emc/emc36.htm>. Acesso em: 10 out. 2015.

Constituição (1988). Emenda constitucional n. $\cong$ 71, de 29 de novembro de 2012.

Disponível em <http://www.planalto.gov.br/ccivil_03/constituicao/Emendas/Emc/emc71.htm>. Acesso em: 10 out. 2015.

Decreto no 8.771, de 11 de maio de 2016. Regulamenta a Lei no 12.965 , de 23 de abril de 2014, para tratar das hipóteses admitidas de discriminação de pacotes de dados na internet e de degradação de tráfego, indicar procedimentos para guarda e proteção de dados por provedores de conexão e de aplicações, apontar medidas de transparência na requisição de dados cadastrais pela administração pública e estabelecer parâmetros para fiscalização e apuração de infrações. Disponível em < http://www.planalto.gov.br/ccivil_03/_Ato2015-2018/2016/Decreto/D8771.htm>. Acesso em: 25 out. 2016.

Governo Federal. Portal da Transparência. Controle social. [200-? ]. Disponível em <http://www.portaldatransparencia.gov.br/controlesocial/>. Acesso em: 10 out. 2015.

Lei n. $\cong 12.965$, de 23 de abril de 2014. Estabelece princípios, garantias, direitos e deveres para o uso da Internet no Brasil. Disponível em <http://www.planalto.gov.br/ccivil_03/_ato20112014/2014/lei/l12965.htm>. Acesso em: 05 out. 2015.

CARTA de Brasília. Disponível em: <http://www2.camara.leg.br/atividadelegislativa/comissoes/comissoes-permanentes/cdhm/noticias/endh_cartabrasilia>. Acesso em: 12 out. 2015. 
CASTELLS, Manuel. Internet e sociedade em rede. In: Por uma outra comunicação: mídia, mundialização cultural e poder. Dênis de Moraes (org.). 6a ed. Rio de Janeiro: Record, 2012, p. 255287.

CUNHA, Newton. Cultura e ação cultural: uma contribuição a sua história e conceitos. São Paulo: Edições SESC SP, 2010.

Dicionário Sesc: a linguagem da cultura. São Paulo: Perspectiva: Sesc São Paulo, 2003.

FERREIRA FILHO, Manoel Gonçalves. Direitos Humanos Fundamentais. 11a ed. rev. e aum. São Paulo: Saraiva, 2009.

FIORILLO, Celso Antonio Pacheco. Curso de Direito Ambiental Brasileiro. São Paulo: Saraiva, 2014.

0 direito de antena em face do direito ambiental no Brasil. São Paulo: Saraiva, 2000.

O Marco Civil da Internet e o Meio Ambiente Digital na Sociedade da Informação: comentários à Lei n. 12.965/2014. São Paulo: Saraiva, 2015a.

Princípios constitucionais do direito da sociedade da informação: a tutela jurídica do meio ambiente digital. São Paulo: Saraiva, 2015b.

FÓRUM NACIONAL pela DEMOCRATIZAÇÃO DA COMUNICAÇÃO. Mídia brasileira é controlada por apenas 11 famílias. Disponível em <http://www.fndc.org.br/noticias/midia-brasileira-e-controladapor-apenas-11-familias-924625/>. Acesso em: 15 out. 2015.

GINDRE, Gustavo. Agenda de regulação: uma proposta para o debate. In: SILVEIRA, Sérgio Amadeu et al. Comunicação Digital e a construção dos commons. São Paulo: Fundação Perseu Abramo, 2007, p. 129-174.

GRUPO GLOBO. Áreas de atuação do Grupo Globo. 2015. Disponível em <http://grupoglobo.globo.com/>. Acesso em: 10 out. 2015.

INSTITUTO DE DEFESA DO CONSUMIDOR. Marco Civil da Internet: regulamentação reforça regras a favor dos usuários. 13 mai. 2016. Disponível em <http://www.idec.org.br/em-acao/emfoco/marco-civil-da-internet-regulamentaco-reforca-regras-a-favor-dos-usuarios>. Acesso em: 23 out. 2016.

INTERVOZES. Coletivo Brasil de Comunicação Social. Vozes Silenciadas: mídia e protestos: a cobertura das manifestações de junho de 2013 nos jornais O Estado de S. Paulo, Folha de S. Paulo e O Globo. São Paulo: Intervozes - Coletivo Brasil de Comunicação Social, 2014. Disponível em <http://intervozes.org.br/arquivos/interliv009vozsmep-baixa.pdf>. Acesso em: 24 out. 2016.

LOWENTAL, Leo. Literature, popular culture and society. Palo Alto, CA: Pacific, 1961, p. II apud STOREY, John. Teoria cultural e cultura popular: uma introdução. Tradução: Pedro Barros. São Paulo: Edições Sesc São Paulo, 2015.

PMDB APRESENTA ALTERNATIVA AO MARCO CIVIL SEM NEUTRALIDADE DE REDE.13 mar. 2014. Disponível em <http://tecnologia.uol.com.br/noticias/redacao/2014/03/13/pmdb-apresentaalternativa-ao-marco-civil-sem- neutralidade-de-rede.htm>. Acesso em: 13 out. 2015. 
PROJETO DE LEI DE INICIATIVA POPULAR DA COMUNICAÇÃO SOCIAL ELETRÔNICA (LEI DA MÍDIA DEMOCRÁTICA). [200-? ]. Disponível em <http://www.paraexpressaraliberdade.org.br/projeto-delei/>. Acesso em: 15 out. 2015.

PROMO INTERNET TURBINADA + R\$ 0,99/DIA. [201-?]. Disponível em <http://www.claro.com.br/celular/promocoes-pre/promocao-pre/regiao/ddd11/SP-11/saopaulo/>. Acesso em: 24 out. 2016.

SILVA, José Afonso da. Curso de direito constitucional positivo. 9a ed. rev. e ampl. de acordo com a nova Constituição. São Paulo: Malheiros, 1994.

TYLOR, Burnett. Primitive Culture, 1871 apud CUNHA, Newton. Dicionário Sesc: a linguagem da cultura. São Paulo: Perspectiva: Sesc São Paulo, 2003.

Trabalho enviado em 26 de setembro de 2016.

Aceito em 01 de novembro de 2016. 